\title{
OIL OR FLAXSEED FLOUR REDUCES PANCREATIC ISLET AREA BUT DOES NOT AFFECT SERUM INSULIN, AT WEANING, IN MALE WISTAR RATS
}

\author{
A. D'Avila Pereira ${ }^{1}$, D. Cavalcante Ribeiro ${ }^{1}$, A. de Sousa dos Santos ${ }^{2}$, B. Ferolla da Camara Boueri ${ }^{1}$, \\ C. Ribeiro Pessanha ${ }^{1}$, M. Duque Coutinho de Abreu ${ }^{1}$, L. Pessoa Rozeno ${ }^{1}$, \\ C. Cristina Alves do Nascimento-Saba ${ }^{2}$, L. Guillermo Coca Velarde ${ }^{3}$, C.A. Soares da Costa ${ }^{1}$, \\ Gilson Teles Boaventura ${ }^{1}$
}

\begin{abstract}
The aim of the present study evaluated the influence of oil or flaxseed flour in pancreas morphology of pups, whose mothers were fed with oil or flaxseed flour during lactation, at weaning. After birth, the lactating rat males were randomly assigned: control ( $\mathrm{C}, \mathrm{n}=12$ pups), flaxseed oil ( $\mathrm{FO}, \mathrm{n}=12$ pups) and flaxseed flour ( $\mathrm{FF}, \mathrm{n}=12)$. At 21 days, the pups were weaning and anesthetized. Body mass, length, serum glucose, insulin, pancreas mass and pancreatic islet area were assessed. FO and FF showed higher $(p<0.05)$ mass and length and lower glucose $(p<0.05)$ when compared with $C$. Insulin $(p=0.094)$ and pancreas mass $(\mathrm{p}=0.054)$ not differ between groups. FO and FF showed lower $(\mathrm{p}<0.05)$ pancreatic islet area when compared with C. A fed with FO or FF, during lactation may improve function pancreatic, as insulin sensitivity. These findings emphasize that oil or flaxseed flour during lactation may improve pancreatic function in early life.
\end{abstract}

Key words: Flaxseed oil, flaxseed flour, rats, lactation, pancreatic islet area.

\section{Introduction}

Mother's milk represents the primary source of nutrition, with relevant importance to body development during the first 12 months following birth (1). However, changes in milk's nutrients represent a risk to future metabolic disturbances in the pancreatic morphology and lead to diabetes mellitus (2).

Pancreas is a mixed organ that release digestive enzymes (exocrine) and hormones (endocrine). Endocrine pancreas is consists by pancreatic islet, compound by alpha cells, insulin-producing, and beta cells, glucagonproducing, both responsible by regulation of glucose, lipids and proteins metabolism. Moreover, insulin acts in growth and development of the organism since has anabolic action (2). Reduction insulin action is associated with type 2 diabetes mellitus, a chronic disease characterized by high levels of blood glucose due insulin resistance (2). This disease may be controlled by daily diet and epidemiological study evidenced that ingestion

1. Laboratory of Experimental Nutrition, Department of Nutrition and Dietetics, Fluminense Federal University, Niterói - Rio de Janeiro, Brazil; 2. Physiological Sciences, Institute of Biology Roberto Alcantara Gomes, State University of Rio de Janeiro, Rio de Janeiro, Brazil; 3. Department of Statistics, Fluminense Federal University, Niterói - Rio de Janeiro, Brazil.

Corresponding Author: Aline D'Avila Pereira Experimental Nutrition Laboratory, College of Nutrition, Federal Fluminense University. Rua Mário Santos Braga, 30, Niterói, RJ, 24015-110, Brazil. E-mail: alinedape@gmail.com Telephone and fax number: +55 2126299860

Received April 24, 2017

Accepted for publication May 29, 2017 of fatty acids may affect insulin secretion and pancreatic islet (3).

In this context, saturated may have more deleterious effects on insulin resistance, whereas polyunsaturated fats as alpha linoleic acids (ALA, 18: $3 n-3$ ) are less detrimental (3). In this context, flaxseed (Linum usitatissimum) has been described as an excellent ALA source, presenting an average of $30 \%$ lipids in its composition, with $51-55 \%$ corresponding to ALA (4).

In Brazil, ALA intake during lactation period needs supervision in agreement with Brazilian National Sanitary Surveillance Agency (ANVISA) recommendations (5). Due to insufficient data, experimental models are needed to provide information regarding safety of flaxseed during lactation period. Thus, the present study was designed to evaluated, at weaning, pancreas morphology in the presence of the diet containing oil or flaxseed flour administered to male rats during lactation period.

\section{Materials and methods}

Protocol used for dealing with experimental animals was approved by the Ethics Committee on Animal Research of the Federal Fluminense University, NiteróiRJ, Brazil (protocol 473/2012). All procedures were performed in accordance with the Brazilian Science and 
Laboratory Animal Society, and the Guide for the Care and Use of Laboratory Animals provisions published by the US National Institutes of Health (NIH Publication N 85-23, revised in 1996).

Wistar rats were kept in temperature-controlled $(23 \pm$ $\left.2^{\circ} \mathrm{C}\right)$, humidity $(60 \pm 10 \%)$, with artificial dark-light cycle (lights on from 7 am to $7 \mathrm{pm}$ ). Virgin female rats caged with males rats ( 3 months old respectively). After mating, each female was placed in an individual cage with free access to water and standard diet (Nuvilabß, Paraná, Brazil).

Within 24 hours of birth, excess pups were removed, and only six male pups were kept per dam, which maximizes lactation performance (6). During lactation period, pups were randomly assigned: control (C, $\mathrm{n}=12$ pups), whose dams were fed with control diet containing $7 \mathrm{~g}$ of soybean oil/100g; flaxseed oil (FO, $\mathrm{n}=12$ pups), whose dams were fed with diet containing $7 \mathrm{~g}$ of flaxseed oil/100g; and flaxseed flour ( $\mathrm{FF}, \mathrm{n}=12$ ), whose dams were fed with diet containing $25 \mathrm{~g}$ of flaxseed flour $/ 100 \mathrm{~g}$, during lactation period respectively, in agreement with American Institute of Nutrition (AIN93G) recommendations (Table 1) (7). Flaxseed oil contains $3.66 \mathrm{~g}$ of $\alpha$-linolenic acid and $0.86 \mathrm{~g}$ of linoleic acid for each 7 g. Flaxseed flour (containing 17\% of protein, $45 \%$ of carbohydrate and $26 \%$ of fat to $25 \mathrm{~g} / 100 \mathrm{~g}$ ), aimed to meet the entire recommended fiber intake and it was not necessary to add oil because this seed is a source of this component (8). Flaxseed flour contains $14.55 \mathrm{~g}$ of $\alpha$-linolenic acid and $3.65 \mathrm{~g}$ of linoleic acid for each $25 \mathrm{~g}$ (9).

Table 1

Composition of experimental diets

\begin{tabular}{lccc}
\hline Ingredient & C & FO & FF \\
\hline Casein, g/100 g & 20.0 & 20.0 & 15.0 \\
Cornstarch, g/100 g & 52.9 & 52.9 & 45.84 \\
Sucrose, g/100 g & 10.0 & 10.0 & 10.0 \\
Soybean oil, g/100 g & 7.0 & - & - \\
Flaxseed flour & - & - & 25.0 \\
Flaxseed oil, g/100 g & - & 7.0 & - \\
Cellulose, g/100 g & 5.0 & 5.0 & - \\
AIN-93G mineral mix, g/100 g & 3.5 & 3.5 & 3.5 \\
AIN-93 vitamin mix, g/100 g & 1.0 & 1.0 & 1.0 \\
L-Cystine, g/100 g & 0.3 & 0.3 & 0.3 \\
Choline bitartrate, g/100 g & 0.25 & 0.25 & 0.25 \\
Tert-Butylhydroquinone (TBHQ), mg/100g & 14.0 & 14.0 & 14.0 \\
Protein, \% of energy & 17.0 & 17.0 & 17.0 \\
Carbohydrate, \% of energy & 54.0 & 54.0 & 49.00 \\
Fat, \% of energy & 7.0 & 7.0 & 7.0 \\
Energy, kcal/100g & 347.2 & 347.2 & 327.00 \\
\hline
\end{tabular}

Formulated based on the American Institute of Nutrition AIN-93G recommendation for rodent diets. Control group (C) flaxseed oil (FO) and flaxseed flour (FF); Mineral and Vitamin Mix; L-Cystine; Choline Bitartrate: PragSoluções ${ }^{\circledR}$; Casein; Cornstarch; Cellulose: FARMOS®; Soybean: Lisa ${ }^{\circledR}$ and Sucrose: União®. Flaxseed: Giroil Agroindustria Ltda, with 3,66g alpha linolenic acid and $0,86 \mathrm{~g}$ linoleic acid for each $7 \mathrm{ml}$ flaxseed oil. Flaxseed flour: ArmaZen (B) with $17 \%$ protein, $45 \%$ carbohydrate and $26 \%$ fat. Formulated on AIN-93G recommendations for rodent diets.
At 21 days, pups were weaned, and after $2 \mathrm{~h}$ of fasting body mass and length $(\mathrm{cm}$, measured as the distance between nose tip and tail tip) were evaluated. They were then anesthetized with Thiopentax (Sodium thiopental, $0.1 \mathrm{mg}$ out $100 \mathrm{~g}$ ). Blood was collected by cardiac puncture. Samples were centrifuged, and the serum were stored at $-80{ }^{\circ} \mathrm{C}$ for later analysis. Serum concentration of glucose $(\mathrm{mg} / \mathrm{dl})$ and insulin $(\mathrm{ng} / \mathrm{ml})$ was measured using multiplex assay kits (Millipore rat panel RBN1MAG31K-03, MA, USA).

Pancreas was dissected and weighed. Masses were expressed as absolute $(\mathrm{g})$ relative $(\mathrm{g} / 100 \mathrm{~g})$ mass (adjusted to body mass). Samples of pancreas tail were fixed in buffered formaldehyde and processed following the routine technique by paraffin inclusion. Serial sections of $5 \mu \mathrm{m}$ thick were stained with hematoxylin-eosin. Sectional pancreatic islets area $(\mu \mathrm{m} 2)$ was determined on digital images using the IMAGE-J software http:/ / rsbweb.nih.gov/ij/.Statistical analyses were performed out using S-plus 8.0 statistical package. The results were analyzed using one-way analysis of variance, followed by Newman-Keuls post-test and expressed as means \pm SEM (standard error of the mean) with significance level of 0.05 .

Table 2

Body mass and length, pancreas mass, serum insulin and pancreatic islet area of pups at 21 days

\begin{tabular}{lcccccc}
\hline & \multicolumn{2}{c}{ C (n12) } & \multicolumn{2}{c}{ FO (n12) } & \multicolumn{2}{c}{ FF (n12) } \\
& Mean & SEM & Mean & SEM & Mean & SEM \\
\hline Body mass, g & $54.42^{\mathrm{a}}$ & 1.79 & $61.08^{\mathrm{b}}$ & 1.17 & $59.04^{\mathrm{b}}$ & 0.36 \\
Length, cm & $18.79^{\mathrm{a}}$ & 0.22 & $20.58^{\mathrm{b}}$ & 0.13 & $19.96^{\mathrm{b}}$ & 0.22 \\
Glucose (mg/dl) & $169.78^{\mathrm{a}}$ & 13.79 & $122.15^{\mathrm{b}}$ & 3.69 & $138.43^{\mathrm{a}}$ & 8.70 \\
Insulin $(\mathrm{ng} / \mathrm{ml})$ & 55.25 & 6.32 & 76.53 & 7.08 & 69.57 & 5.60 \\
Pancreas mass, g & 0.1858 & 0.0137 & 0.2336 & 0.0096 & 0.1881 & 0.0183 \\
Pancreas mass, g/100g & 0.3415 & 0.0224 & 0.3844 & 0.0237 & 0.3177 & 0.0300 \\
Pancreatic islet area, $\mu \mathrm{m}^{2}$ & 5990 & 928.3 & $3265 \mathrm{~b}$ & 207.2 & $4085 \mathrm{~b}$ & 493.3 \\
\hline
\end{tabular}

Control group $(\mathrm{C}, \mathrm{n}=12)$, flaxseed oil group $(\mathrm{FO}, \mathrm{n}=12)$ and flaxseed flour group $(\mathrm{FF}, \mathrm{n}=12)$ at 21 days. SEM=standard error of the mean. $\mathrm{a}, \mathrm{b}$ Values with different superscripts are significantly different (One-way ANOVA, $\mathrm{p}<0.05$ ).

Statistical analyses were performed out using S-plus 8.0 statistical package. The results were analyzed using one-way analysis of variance, followed by NewmanKeuls post-test and expressed as means \pm SEM (standard error of the mean) with significance level of 0.05 .

\section{Results}

Pups whose mothers consumed diet containing oil or flour showed higher body mass $(+12 \%, \mathrm{p}<0.001$ and $+8 \%$, $\mathrm{p}<0.05$, respectively) and length $(+9 \%, \mathrm{p}<0.0001$ and $+6 \%$, $\mathrm{p}<0.0001)$ compared to $C$ group. About serology analysis, the intake of oil and flour promoted lower serum glucose $(-28 \%, \mathrm{p}<0.001$ and $-18 \%, \mathrm{p}<0.05)$. Insulin, absolute and 
relative pancreas mass were similar between groups $(p=0.094, p=0.054$ and $p=0.17$, respectively). Pancreatic islets areas were lower in FO $(-45 \%, \mathrm{p}<0.001)$ and $\mathrm{FF}$ $(-31 \%, \mathrm{p}<0.05)$ regarding $\mathrm{C}$ group (Table 2$)$.

\section{Discussion}

In present study, control and experimental diets contain similar energy and lipids content. However, control group was treated with diet containing high concentration linoleic acid (LA, 18:2 n-6) provided by soybean oil, while oil and flaxseed flour diets contains high ALA concentrations. Although has not assessed fatty acid composition in breast milk, previous studies showed higher ALA and lower levels of arachidonic acid (derived of LA) in serum of rats treated with flaxseed (10, 11) and flaxseed oil (12). Probably body mass, pup length, glucose serum and pancreatic morphology findings may be related with fatty acid composition of diets intake during lactation period.

Although there are limited studies regarding effects of polyunsaturated fatty acids on pancreatic cells, Hwang et al. (13) related that ALA may reduce the risk of progression from prediabetes to diabetes. Wang et al. (14) observed that ALA prevent hyperglycemia and preserve functional $\beta$-cells mass attenuating apoptosis by suppression of lipogenic gene expression, particularly sterol regulatory element-binding protein-1 (SREBP-1) that is a contributory factor to subsequent $\beta$-cells dysfunction/death. In addition, hypertrophy of pancreatic islet is associated with overstimulation, higher insulin release and reduction insulin sensitivity (15). These pathways help suggest that ALA fatty acids provided by oil and flaxseed flour preserving the pancreatic $\beta$-cells and contributed to insulin sensitivity, because FO and FF groups showed high body development at weaning.

Both oil and flaxseed flour act on the findings of this study. However, was observed that flaxseed oil may has provided better pancreatic results. Comparing one with the other, although there were no significant difference, body mass and length $(+3 \%$, respectively) were higher, while serum glucose $(-12 \%)$ and pancreatic islet $(-20 \%)$ were lower in FO. The flaxseed oil added in the FO diet has, in its composition centesimal, only fatty acid n-3 e n-6 and flaxseed flour added in the FF diet has, in its composition centesimal, vegetal protein, carbohydrate, fatty acid n-3 e n-6 and fibers, as lignin (9). These differences in the compositions may explain theses finding, because the ALA may be more bioavailable in the oil when compared to flour. Nonetheless, more studies must be carried out to understand the action of flaxseed properties and its effects on pancreas physiology.

Despite preliminary analysis, these findings emphasize that ALA-rich diets, as oil or flaxseed flour diets, during lactation may improve pancreatic function in early life.

Acknowledgements: The authors are thankful to Coordination for the Enhancement of Higher Education Personnel (CAPES) and National Counsel of Technological and Scientific Development (CNPq).

Funding: This work was funded by The State of Rio de Janeiro Carlos Chagas Filho Research Foundation (grant number 103373/2012).

Conflict of interest: The authors declare that there no conflict of interest..

Ethocal standard: ?????

\section{References}

1. Roszkowska R, Taranta-Janusz K, Tenderenda-Banasiuk E, Wasilewska A. The effects of breastfeeding on serum asymmetric dimethylarginine levels and body composition in children. Breastffed Med 2015;10:38-44.

2. Hochberg Z. Evo Devo of child growth: treatise on child growth and human evolution. 2012. Miley, New York

3. Gravena C, Mathias PC, Ashcroft SJH. Acute effects of fatty acids on insulin secretion from rat and human islets of langerhans. J Endocrinol 2002;173:7380

4. Leite KDFC, Vicente GC, Suzuki A, et al. Effects of flaxseed on rat milk creamatocrit and its contribution to offspring body growth. J Pediatr 2012;88:74-78

5. Silveira TFV, Vianna CMM, Mosegui GBG. Brazilian legislation for functional foods and the interface with the legislation for other food and medicinal classes: contradictions and omissions. Physis 2009;19:1189-1202.

6. Fishbeck KL, Rasmussen KM. Effect of repeated cycles on maternal nutritional status, lactational performance and litter growth in ad libitum-fed and chronically foodrestricted rat. J Nutr 1987;117:1967-1975.

7. Reeves PG. Components of the AIN-93 diets as improvements in the AIN76A diet. J Nutr 1997;127:838-841.

8. Boueri BFC, Pessanha CR, Costa LR, et al. Body composition in male rats subjected to early weaning and treated with diet containing flour or flaxseed oil after 21 days until 60 days. J Dev Orig Health Dis 2015;6:553-557.

9. Morris, DH. Flax - A Health and Nutrition Primer. 2007. Flax Council of Canada, Canada.

10. Costa CAS, Silva PC, Ribeiro DC, et al. Body adiposity and bone parameters of male rats from mothers fed diet containing flaxseed flour during lactation. J Dev Orig Health Dis 2015;7:1-6.

11. Ribeiro DC, Pereira AD, Silva PC, et al. Flaxseed flour (Linum usitatissinum) consumption improves bone quality and decreases the adipocyte area of lactating rats in the post-weaning period. Int J Food Sci Nutr 2016;67:29-34.

12. Pereira AD, Ribeiro DC, Santana FC, et al. Maternal flaxseed oil during lactation enhances bone development in male rat pups. Lipids 2016;51:923929.

13. Hwang WM, Bak DH, Kim DH, et al. Omega-3 Polyunsaturated Fatty Acids May Attenuate Streptozotocin-Induced Pancreatic $\beta$-Cell Death via Autophagy Activation in Fat1 Transgenic Mice. Endocrinol Metab 2015;30:569-575.

14. Wang J, Song MY, Bae UJ, Lim JM, Kwon KS, Park BH. n-3 Polyunsaturated fatty acids protect against pancreatic $\beta$-cell damage due to ER stress and prevent diabetes development. Mol Nutr Food Res 2015;59:1791-1802.

15. Slavin BGI, Zarow C, Warden CH, Fisler JS. Histological, immunocytochemical, and morphometrical analyses of pancreatic islets in the BSB mouse model of obesity. Anat Rec 2010;293:108-116. 